\title{
INFECÇÃO PELO HERPES VIRUS HUMANO TIPO 6 (HHV6) EM UM GRUPO DE RECEPTORES DE TRANSPLANTE RENAL
}

\author{
Type 6 human herpes virus (hhv6) infection in a group of Brazilian renal transplant recipients
}

\author{
Janaína Luisa Leite', Juliana Andréa Manfrinatto ${ }^{2}$, Marilda Mazzali² e Laura Sterian Ward ${ }^{1}$
}

\begin{abstract}
RESUMO
Com o advento de imunossupressores mais potentes, infecções virais têm se tornado uma importante complicação pós-transplante. Apesar do herpes vírus tipo 6 (HHV6) ser um patógeno freqüente na população humana, a prevalência de infecção e a associação com complicações pós-transplante permanece controversa. Objetivo: Identificar a prevalência de infecção pelo HHV6, fatores de risco e complicações após transplante renal. Métodos: Foi realizada PCR para HHV6 em amostras de sangue de 71 receptores de transplante renal, em média 12 meses pós-transplante, e comparadas com um grupo controle de 112 indivíduos saudáveis, doadores de sangue. Resultados: a prevalência de PCR positivo para HHV6 foi significativamente maior no grupo de transplantados renais ( $36 \%$ vs.11\%, p<0.05). Para a identificação de fatores de risco e de complicações da infecção pelo HHV6 pós-transplante, os pacientes foram divididos em dois grupos: HHV6 positivo e HHV6 negativo. Os grupos foram semelhantes na comparação dos parâmetros demográficos, sorologia para hepatite B, C ou CMV, medicação imunossupressora ou uso de terapia de indução. Entretanto, o grupo HHV6+ apresentou maior incidência de leucopenia, elevação de aminotransferases, doença por citomegalovírus sintomática e outras infecções virais associadas. Apesar da baixa incidência de rejeição aguda em ambos os grupos, a taxa de filtração glomerular foi menor no grupo HHV6+ ao final de dois anos de acompanhamento. Conclusão: A infecção por HHV6 foi mais freqüente em receptores de transplante renal que na população controle, e apresentou associação com maior incidência de infecção sintomática por CMV e outras infecções virais, além de redução de taxa de filtração glomerular.
\end{abstract}

Descritores: Citomegalovirus, Herpes Vírus 6, Transplante Renal, Infecção Viral.

Instituição:

Departamento de Clínica Médica, FCM Unicamp, Campinas, São Paulo, Brasil

1. Laboratório de Genética Molecular do Câncer

2. Laboratório de Nefrologia I - Disciplina de Nefrologia

Correspondência:

Prof. Dra Marilda Mazzali

Disciplina de Nefrologia - DCM/FCM Unicamp

Rua Tessália Vieira de Camargo 126 - Cidade Universitária Zeferino Vaz

CEP 13083-970 Barão Geraldo - Campinas - São Paulo - Brasil

Tel./Fax: 5519 3521-7959

Email: mmazzali@fcm.unicamp.br / mazzma@uol.com.br

Recebido em: 25.09.2006

Aceito em: 16.10.2006

\section{INTRODUÇÃO}

Herpes vírus humanos são altamente distribuídos em populações humanas e persistem na forma latente após a infecção primária. Infecções virais latentes são comuns em receptores de transplantes de órgãos, podendo ser reativados com a utilização de medicação imunossupressora. Outro fator de risco para infecção viral é a contaminação por doador positivo para doador negativo, com o desenvolvimento de primo-infecção, habitualmente com apresentação clínica mais grave ${ }^{1}$.

Os herpes vírus tipo 6 são beta herpes vírus, que apesar de não apresentarem patogênese completamente elucidada, podem atuar como importantes agentes de infecções oportunistas em presença de imunodepressão ${ }^{2}$. A infecção primária pelo HHV6 ocorre na infância, e cerca de $90 \%$ das crianças com menos de dois anos de idade apresentam sorologia positiva ${ }^{3}$. Após a infecção primária, o HHV6 permanece sob a forma latente em macrófagos e monócitos de diferentes tecidos, como pele, pulmões e cérebro ${ }^{4}$. A reativação pode ocorrer após o transplante, mas seu significado clínico permanece controverso pela alta prevalência de sorologia positiva, associada a outros herpes vírus e à ausência de grandes estudos populacionais ${ }^{4}$. A apresentação clínica do HHV6 varia da forma assintomática à febre, supressão de medula óssea, encefalite, hepatite, pneumonite, e pode facilitar episódios de rejeição aguda, especialmente em receptores pediátricos de transplante renal ${ }^{5,6}$. 
A associação entre HHV6 e citomegalovírus foi descrita ${ }^{7-10}$. Alguns autores relatam que a co-infecção com HHV6 ou HHV7 aumenta o risco de infecções sintomáticas pelo $\mathrm{CMV}^{10-12}$, além de episódios de rejeição ${ }^{6}$. Por outro lado, a doença pelo CMV também pode causar reativação do $\mathrm{HHV6}^{13-15}$.

O objetivo do presente estudo foi avaliar a incidência e impacto clínico da infecção pelo HHV6 na evolução de receptores de transplante renal. Como a real prevalência dessas infecções virais em nossa região ainda é insuficiente, inicialmente comparamos a prevalência de HHV6 em receptores de transplante com uma população controle. Na população de transplantados também foram analisados os fatores de risco para infecção por HHV6, bem como o impacto da infecção pelo HHV6 na evolução de paciente e enxerto.

\section{MÉTODOS}

O estudo foi aprovado pelo Comitê de Ética em Pesquisa da Faculdade de Ciências Médicas da UNICAMP, e o consentimento informado foi obtido de todos os sujeitos envolvidos. Pacientes e controles foram submetidos à avaliação médica, com registro das condições médicas pré-existentes, especialmente relacionadas ao transplante, medicação imunossupressora, e outras infecções virais (Hepatite B e C, CMV).

O grupo de pacientes (Grupo I) foi constituído de 71 receptores de transplante renal (41 homens e 30 mulheres, com idade média de 42 \pm 12 anos), em acompanhamento regular por pelo menos 12 meses pós-transplante, com função renal preservada (creatinina sérica < $2 \mathrm{mg} / \mathrm{dl}$ ) e sob imunossupressão regular. Todos os casos seguiram o protocolo padrão do serviço, com realização de sorologias prétransplante, para doador e receptor, de CMV, hepatite B e C, HIV e Epstein Barr. Os prontuários médicos foram revisados para coleta de informações adicionais sobre doenças prévias, imunossupressão e terapia antiviral pós-transplante.

O regime de imunossupressão de manutenção foi baseado em associação de esteróides, inibidores de síntese de purinas (azatioprina ou micofenolato mofetil) e inibidor de calcineurina (ciclosporina ou tacrolimus), de acordo com o protocolo local. Episódios de rejeição aguda foram confirmados através de biópsia e tratados com terapia em pulso com metilprednisolona.

O grupo controle (Grupo II), composto por 112 indivíduos saudáveis (49 homens e 63 mulheres, idade média de $32 \pm 10$ anos) foi recrutado a partir de doadores de sangue do Hemocentro da Unicamp. Informações sobre história social e ocupacional, condições médicas, doenças prévias e medicamentos em uso foram obtidos através de entrevistas.

Amostras de sangue, extração de DNA e realização de PCR: amostras de sangue foram obtidas dos sujeitos de ambos os grupos. Células mononucleares de sangue periférico (pbmcs) foram isoladas através de centrifugação, lavadas e estocadas em freezer $-20^{\circ} \mathrm{c}$ até o uso. $\mathrm{O}$ DNA foi extraído através de técnica fenol/clorofórmio e precipitação em etanol, e os extratos estocados em freezer a $-20^{\circ} \mathrm{c}$.

A concentração de DNA foi determinada através de espectrofotometria. A amplificação das seqüências de HHV6 foi realizada através de Nested-PCR, com dois grupos de primers. O primeiro grupo amplificava a região correspondente à proteína maior de capsídeo, com primers externos reconhecendo uma seqüência de 520 pares de bases (primers E1 e E2) e a seqüência interna reconhecendo um fragmento de $258 \mathrm{pb}$ (primers 13 e 14). O segundo grupo de primers reconhecia a região de proteína de tegumento viral, com os iniciadores externos de reação reconhecendo uma região de $834 \mathrm{pb}$ (primers $\mathrm{A} 1$ e C1) e primers internos reconhecendo seqüência de 658 $\mathrm{pb}$ (primers A3 e C3). Todas as reações de PCR foram realizadas em termocicladora programável (Perkin-Elmer), utilizando volume final de $25 \mu$ incluindo $200 \mathrm{ng}$ de DNA, $50 \mathrm{~mm} \mathrm{KCl}, 20 \mathrm{~mm}$ tris$\mathrm{HCl}, 15 \mathrm{~mm} \mathrm{MgCl}$ 2, $0.2 \mathrm{~mm}$ dntp, e $3 \mathrm{u}$ de taq dna polimerase (Life Technologies Gibco brl). A concentração de primers E1/E2 (5'-GCG TTT TCA GTG TGT AGT TCG GCA g-3' / 5'-TGG CCG CAT TCG TAC AGA TAC GGA GG-3') foi de $25 \mu \mathrm{m}$, com temperatura de anelamento de $56^{\circ} \mathrm{C}$. Após 35 ciclos, $2 \mu$ do produto do PCR foi utilizado como base para a segunda reação de amplificação, utilizando os primers 13/14 (5'-GCT AGA ACG TAT TTG CTG CAG AAC g-3' / 5'-ATC CGA AAC AAC TGT CTG ACT GGC A-3') sob as mesmas condições. Quando o segundo grupo de primer (A/C) foi utilizado, a primeira reação utilizou $25 \mu \mathrm{m}$ de cada primer externo, al/cl (5'GTG GAT CCG ACG TCC TAC AAA CAC-3' / 5'-CGG TGT CAC ACA GCA TGA ACT CTC-3'), durante 30 ciclos, com temperatura de anelamento de $58^{\circ} \mathrm{C}$. Após a primeira amplificação, $2 \mu$ do produto do PCR foi utilizado como base para a segunda amplificação A2/C2 (5'-GGA GAA TCT TGT AAG TAT ATG GTC-3' / 5'-CTC GGA CTC ATA GAT CTC ATA CTG-3'), com 20 ciclos, temperatura de anelamento de $58^{\circ} \mathrm{C}$, seguido de 10 ciclos de anelamento a $56 \mathrm{C}$ por $1 \mathrm{e}$ extensão a $72^{\circ} \mathrm{C}$ por 2 min. Amplificação do gene da beta globina foi utilizada como controle de qualidade de DNA. Controle positivo para HHV6 foi obtido através de material de pacientes com infecção ativa e de controles positivos comerciais. Os produtos de amplificação foram visualizados em gel de agarose a $2 \%$ utilizando brometo de etídio como cromógeno, e quantificados quanto à presença de fragmentos de capsídeo de HHV6 (258pb, proteína de capsídeo) e de tegumento (658pb, proteína de tegumento).

Análise estatística utilizou os programas SAS (Statistical Analysis System, versão 8.1, SAS Institute Inc, Cary, NC, USA, 1999-2000) e Statview versão 2 . A homogeneidade da amostra para idade e sexo foi testada através de testes de q quadrado $\left(\mathrm{X}_{2}\right)$ ou exato de Fisher $(\mathrm{F})$. Odds Ratio (OR) e intervalo de confiança de $95 \%$ (CI) foram utilizados para os demais parâmetros. Variáveis numéricas foram expressas em média \pm desvio padrão, e a comparação entre grupos realizada através de teste T. Significância estatística foi considerada se $\mathrm{p}<0,05$.

\section{RESULTADOS}

A freqüência de infecção por HHV6 foi superior no grupo de pacientes comparado ao grupo controle ( $36 \%$ vs. $11 \%$, f; $\mathrm{p}<0,0001)$.

Com o intuito de avaliar fatores de risco e impacto clínico da infecção pelo HHV6 pós-transplante renal, o grupo de pacientes (Grupo I) foi dividido em dois subgrupos: HHV6 positivo $(n=26,15$ homens e 11 mulheres, $38 \pm 11$ anos) e HHV6 negativo ( $n=45,30$ homens e 15 mulheres, $42 \pm 12$ anos). Os dois grupos foram comparáveis em relação à idade, ao sexo, à raça, ao tempo de acompanhamento póstransplante, à doença renal primária, às sorologias pré-transplante (hepatite B, C, HIV e CMV) e ao tipo de doador (vivo relacionado $\mathrm{x}$ falecido). Também não houve diferença na necessidade de terapia de indução com Okt3 ou anticorpo anti-Cd25, nem no regime imunossupressor pós-transplante (Tabela 1).

A avaliação do acompanhamento desses pacientes mostrou maior incidência de leucopenia no grupo HHV6 positivo (69,3\% vs. 13,3\%, $\mathrm{p}<0,05$ ), bem como de elevação de aminotransferases (ALT e AST) acima de duas vezes o valor da normalidade $(50 \%$ vs. $6,6 \%, \mathrm{p}<0,05)$, 
independente do status sorológico para hepatite (Tabela 2). A incidência de doença sintomática ou invasiva pelo CMV foi maior no grupo HHV6 positivo $(23,1 \%$ vs. $11 \%, \mathrm{p}<0,05)$, bem como a duração do tratamento com ganciclovir, independente da sorologia de CMV pré-transplante. Outras infecções virais também foram mais prevalentes no grupo HHV6 positivo (Tabela 3).

Tabela 1: Dados demográficos dos receptores de transplante renal de acordo com a presença de infecção pelo HHV6.

\begin{tabular}{lccc}
\hline & $\begin{array}{c}\text { HHV6 } \\
\text { POSITIV0 }\end{array}$ & $\begin{array}{c}\text { HHV6 } \\
\text { NEGATIV0 }\end{array}$ & P \\
\hline Número de pacientes & 26 & 45 & \\
Sexo (masculino: feminino) & $15: 11$ & $30: 15$ & $<0,05$ \\
Idade (anos) & $38 \pm 11$ & $42 \pm 12$ & \\
Acompanhamento pós-transplante (meses) & $12 \pm 04$ & $11 \pm 05$ & \\
Doador (falecido: vivo relacionado) & $19: 7$ & $30: 15$ & \\
Terapia de indução (\%) & $34.6 \%$ & $22.2 \%$ & \\
Azatioprina: MMF & $7: 15$ & $16: 29$ & \\
Ciclosporina: tacrolimus & $20: 3$ & $34: 6$ B & \\
Rejeição aguda por biopsia (\%) & $19.2 \%$ & $33.3 \%$ & $<0,05$ \\
\hline
\end{tabular}

Dados apresentados como média \pm desvio padrão. B em ambos os grupos pacientes com HLA idêntico, em regime de imunossupressão livre de ciclosporina.

Tabela 2: Alterações laboratoriais nos grupos de transplante de acordo com o PCR para HHV6.

\begin{tabular}{lccc}
\hline & $\begin{array}{c}\text { HHV6 } \\
\text { POSITIV0 }\end{array}$ & $\begin{array}{c}\text { HHV6 } \\
\text { NEGATIV0 }\end{array}$ & P \\
\hline Número de pacientes & 26 & 45 & \\
Leucopenia (WBC $<4.000 / \mathrm{mm} 3)(\%)$ & $69,2 \%$ & $13,3 \%$ & $<0,05$ \\
Elevação de aminotransferases $>2 \times$ normal $(\%)$ & $50 \%$ & $4,4 \%$ & $<0,05$ \\
Creatinina sérica após 2 anos $(\mathrm{mg} / \mathrm{dl})$ & $2,6 \pm 2,0$ & $1,6 \pm 0,6$ & $<0,05$ \\
\hline
\end{tabular}

Resultados em média \pm desvio

$W B C=$ leucócitos

Tabela 3: Infecções virais em receptores de transplante renal de acordo com o status de PCR para HHV6.

\begin{tabular}{lccc}
\hline & $\begin{array}{c}\text { HHV6 } \\
\text { POSITIV0 }\end{array}$ & $\begin{array}{c}\text { HHV6 } \\
\text { NEGATIV0 }\end{array}$ & P \\
\hline Número de pacientes & 26 & 45 & \\
Citomegalovírus (\%) & $23,1 \%$ & $11,1 \%$ & $<0,05$ \\
Tratamento com ganciclovir (\%) & $23 \%$ & $8,1 \%$ & $<0,05$ \\
Hepatite B (\%) & $7,6 \%$ & $6,6 \%$ & \\
Hepatite C (\%) & $19,2 \%$ & $24,4 \%$ & \\
Outras infecções virais (\%) & $30 \%$ & $8,8 \%$ & $<0,05$ \\
\hline
\end{tabular}

Apesar da incidência de rejeição aguda comprovada por biópsia ser menor no grupo HHV6 positivo $(19,2 \%$ vs. $33 \%$, p $<0,05)$, a função renal destes pacientes foi pior que a do grupo HHV6 negativo ao final

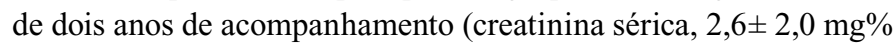
vs. $\left.1,6 \pm 0,6 \mathrm{mg}^{\circ}, \mathrm{p}<0,05\right)$.

\section{DISCUSSÃO}

Utilizando metodologia baseada em PCR qualitativo, detectamos fragmentos de DNA de HHV6 no sangue de 11\% dos indivíduos saudáveis de nossa região. Esta taxa foi inferior à observada em estudos de soroprevalência em outras áreas geográficas do Brasil, com características sócio-demográficas distintas ${ }^{16}$. Aqueles estudos utilizaram testes sorológicos indicando contato prévio com o vírus. No presente estudo, utilizamos um método sensível de reação em cadeia de polimerase (PCR), para avaliar o efeito da infecção ativa por HHV6 numa população controle comparado à outra com alto risco de infecções oportunistas ${ }^{1,17}$. O HHV6 foi cerca de três vezes mais prevalente na população de transplantados (36\%) que nos controles da mesma área geográfica, com background comparável. Essa incidência de HHV6 positivo em população de transplantados é consistente com estudos anteriores, com relatos de incidência de 33 a $88 \%$, de acordo com o método diagnóstico utilizado ${ }^{1,2}$.

Considerando que o HHV5 (CMV) é provavelmente a infecção viral mais importante após transplante renal, vários estudos sugerem que outros herpes vírus (HHV6 e HHV7) também sofreriam ativação após o início da imunossupressão, promovendo sinais e sintomas clínicos ${ }^{1,9,10,12,13,18}$. Na presente série, observamos que pacientes com HHV6 positivo apresentaram maior incidência de infecção sintomática ou invasiva pelo $\mathrm{CMV}$, além de facilitação de outras infecções virais, bem como maior incidência de leucopenia e de alterações de aminotransferases (AST e ALT).

Considerando que infecções por herpes vírus humano são freqüentes e a utilização cada vez maior de medicamentos imunossupressores mais potentes, a incidência de infecção por herpes vírus vem aumentando após o transplante ${ }^{2,15}$. A associação entre infecção pelo HHV6 e doença renal pós-transplante não é bem estabelecida, uma vez que a maioria dos pacientes já apresentou contato anterior com o vírus, resultando em alta prevalência de soropositividade variando de $12 \%$ a $82 \%^{2,19}$. A apresentação habitual da infecção pelo HHV6 é assintomática ou através de febre e/ou rash cutâneo, e sua relevância permanece controversa tanto em indivíduos normais como em imunodeprimidos ${ }^{1,2,19}$. Entretanto, com a utilização de imunossupressores, a reativação de infecções virais prévias pode estar associada a apresentações clínicas mais severas, como leucopenia, hepatite, pneumonite e encefalites ${ }^{2,3,5}$. Alguns estudos sugerem que a ativação de um ou mais beta herpes vírus poderia explicar a apresentação mais severa da doença ${ }^{14}$. O maior risco de episódios de rejeição aguda e de infecções bacterianas e/ou fúngicas oportunistas também estão relacionadas com as infecções por herpes vírus ${ }^{5,20}$. Todos esses fatores promovem impacto negativo na sobrevida do paciente e do enxerto. Na presente série, apesar da menor incidência de rejeição aguda comprovada por biópsia no grupo HHV6 positivo, observamos pior função renal do enxerto ao final de dois anos de acompanhamento. Essa disfunção do enxerto pode ser atribuída tanto à redução da imunossupressão (especialmente MMF) pela ocorrência de leucopenia, como também à ocorrência de episódios de rejeição subclínica. Por se tratar de estudo retrospectivo sem realização de biópsias renais protocolares, a análise da disfunção tardia do enxerto fica prejudicada. Da mesma forma, alguns estudos sugerem que o HHV6 possa invadir o parênquima renal, com alterações citopáticas de epitélio tubular e conseqüente risco de progressão de nefropatia ${ }^{5}$. 


\section{CONCLUSÃO}

Na presente série, a presença de infecção pelo HHV6 esteve associada à infecção mais severa pelo CMV e com função reduzida do enxerto em longo prazo. Estudos prospectivos são necessários para que se estabeleça o real impacto da co-infecção pelo HHV6, tanto na apresentação clínica da doença por CMV como na sobrevida do enxerto.

\section{AGRADECIMENTOS}

Elaine C. Morari, Fabiana Granja e Marcia R. Messaggi, que disponibilizaram as amostras do grupo controle; e a Elizabeth Santos Costa e Sandra Andrella pela coleta de sangue dos pacientes transplantados.

\section{ABSTRACT}

Purpose: HHV6 infections are common in humans. However, the frequency and its association with post-transplant complication remains controversial. In recent years, viral infections have an increasing importance as a post-transplant complication, especially after the development of more potent immunosuppressant drugs. The aim of this study was to identify the prevalence of HHV6 and its complications in stable renal transplant recipients. Methods: HHV6 PCR was performed in 71 blood samples obtained from renal transplant recipients in an average 12 months after transplant, comparing them to a control group of 112 healthy blood donors from the same geographic area. Results: Prevalence of positive HHV6 PCR was significantly higher in the transplant population $(36 \%$ vs. $11 \%$, p $<0.05)$. In order to identify risk factors for HHV6 infection and its complications, the transplant recipients were divided in 2 groups, according to the viral PCR status. No differences in demographic parameters, serological status for Hepatitis B, C or Cytomegalovirus, immunosuppressant regimen or induction therapy was observed between groups. However, HHV6 positive patients presented higher incidence of leukopenia, increased aminotransferase, symptomatic or invasive Cytomegalovirus infection and associated viral infections, such as Herpes or Polyomavirus. Despite the lower incidence of acute rejection episodes, the glomerular filtration rate was reduced in the HHV6 positive group after two years of follow-up. Conclusion: In summary, HHV6 was more frequent in renal transplant patients than in the normal controls. HHV6 infection was associated to a higher incidence of symptomatic or systemic Cytomegalovirus and other viral infections, and reduced graft function.

Keywords: Cytomegalovirus, Herpes Virus 6, Kidney Transplantation, Viral Diseases.

\section{REFERÊNCIAS}

1. Smith SR, Butterly DW, Alexander BD, Grrenberg A. Viral infections after renal transplantation. Am J Kidney Dis. 2001;37(4): 659-76.

2. Singh N, Carrigan DR. Human herpes virus 6 in Transplantation. Ann Int Med. 1996;124 (12):1065-71.

3. Leach CT, Sumaya CV, Brown NA. Human herpes virus 6: clinical implications of a recently discovered, ubiquitous agent. J Pediatr. 1992; 121(2):173-81.

4. Gentile G. Post transplant HHV6 disease. Herpes. 2000;7(1):24-7.

5. Accot PD, Lee SH, Bitter-Suermann H, Lawen JG, Crocker JF. Infections concomitant with pediatric renal allograft rejection. Transplantation. 1996;62:689-91.

6. Wade A, McDonald A, Accot PD, Lee S, Crocker JF. Human herpes virus 6 (HHV6) or Epstein Barr virus (EBV) infection and acute allograft rejection in pediatric kidney transplant recipients. Greater risk for immunologically naive recipients. Transplant Proc. 1998;30:2091-93.

7. Osman HK, Peiris JS, Taylor CE, Karlberg JP, Madeley CR. Correlation between the detection of viral DNA by the polymerase chain reaction in peripheral blood leukocytes and serological responses to human herpesvirus 6, human herpesvirus 7, and cytomegalovirus in renal allograft recipients. J Med Virol. 1997;53(3):288-94.

8. DesJardin JA, Cho E, Supran S, Gibbons L, Werner BG, Snydman DR. Association of human herpesvirus 6 reactivation with severe cytomegalovirus-associated disease in orthotopic liver transplant recipients. Clin Infect Dis. 2001;33(8):1358-62.

9. DesJardin JA, Gibbons L, Cho E, Supran SE, Falagas ME, Werner BG, et al. Human herpesvirus 6 reactivation is associated with cytomegalovirus infection and syndromes in kidney transplant recipients at risk for primary cytomegalovirus infection. J Infect Dis. 1998;178(6):1783-86.

10. Ratnamohan VM, Chapman J, Howse H, Bovington K, Robertson P, Byth K, et al. Cytomegalovirus and human herpesvirus 6 both cause viral disease after renal transplantation. Transplantation. 1998;66(7):877-82.
11. Pacsa AS, Essa S, Voevodin A, el-Shazly A, Kazak H, Nampoory MR, et al. Correlation between CMV genotypes, multiple infections with herpesviruses (HHV-6, 7) and development of CMV disease in kidney recipients in Kuwait. FEMS Immunol Med Microbiol. 2003;35(2):125-30.

12. Humar A, Malkan G, Moussa G, Greig P, Levy G, Mazzulli T. Human herpesvirus-6 is associated with cytomegalovirus reactivation in liver transplant recipients. J Infect Dis. 2000;181(4):1450-53.

13. Dockrell DH, Prada J, Jones MF, Patel R, Badley AD, Harmsen WS, et al. Seroconversion to human herpesvirus 6 following liver transplantation is a marker of cytomegalovirus disease. J Infect Dis. 1997;176(5):1135-40.

14. Humar A, Kumar D, Raboud J, Caliendo AM, Moussa G, Levy G, et al. Interactions between cytomegalovirus, human herpesvirus- 6 , and the recurrence of hepatitis $\mathrm{C}$ after liver transplantation. Am J Transplant. 2002 May;2(5):461-6.

15. Jha R, Narayen G, Sinha S, Kadeer K, Prasad KN. Symptomatic herpes virus infections in postrenal transplant. Transplant Proc. 2003;35(1):284-5.

16. de Freitas RB, Linhares AC. Prevalence of human herpesvirus 6 antibody in the population of Belem, Para, northern Brazil. Trans R Soc Trop Med Hyg. 1997;91(5):538-40.

17. Rubin RH. Infectious disease complications of renal transplantation. Kidney Int. 1993;Jul;44(1):221-36.

18. Accot PD, Lawen J, Lee S, Crocker JFS. Basiliximab versus ATG/ALG induction in pediatric renal transplants: comparison of herpes virus profile and rejection rates. Transplant Proc. 2001;33:3180-3.

19. Okuno T, Higashi K, Shiraki K, Yamanishi M, Takahashi M, Kokado Y et al. Human herpes virus 6 infection in renal transplantation. Transplantation. 1990;49:519-22.

20. Dockrell DH, Mendez JG, Jones MF, Harmsen WS, Ilstrup DM, Smith TF et al. Human herpes virus 6 seronegativity before transplantation predicts the occurrence of fungal infection in liver transplant recipients. Transplantation. 1999;67:399-403 